\title{
RLIP76: A Target for Kidney Cancer Therapy
}

\author{
Sharad S. Singhal, Jyotsana Singhal, Sushma Yadav, Mukesh Sahu, Yogesh C. Awasthi, \\ and Sanjay Awasthi \\ Department of Molecular Biology and Immunology, University of North Texas Health Science \\ Center, Fort Worth, Texas
}

\begin{abstract}
RLIP76 is a multifunctional transporter protein that serves as an energy-dependent efflux mechanism for endogenously generated toxic metabolites as well as exogenous toxins, including chemotherapy drugs. Our recent studies in cultured cells, syngeneic animal tumor model, and in xenograft model have shown that RLIP76 serves a major cancer-specific antiapoptotic role in a wide variety of histologic types of cancer, including leukemia, melanoma, colon, lung, prostate, and ovarian cancer. Results of present studies in cell culture and xenograft model of Caki- 2 cells show that RLIP76 is an important anticancer for kidney cancer because inhibition of RLIP76 function by antibody or its depletion by small interfering RNA or antisense DNA caused marked and sustained regression of established human kidney xenografts of Caki-2 cells in nude mouse.
\end{abstract}

\section{Introduction}

Almost 55,000 people in the United States are diagnosed with kidney cancer each year, and early diagnosis and effective surgical therapy are necessary for its cure. Surgical therapy frequently fails in more advanced stages with involvement of renal vein, lymph nodes, or invasion through the renal cortex (1-5). Highly drug/radiation-resistant nature of kidney cancer compared with other neoplasm is the major reason why there is still no effective and life-prolonging traditional chemotherapy for kidney cancer. Introduction of multispecific kinase inhibitors sorafenib (BAY 43-9006; Nexavar, Bayer) and sunitinib (SU011248; Sutent, Pfizer) to the clinical arena has revolutionized the therapy of advanced kidney cancer (6-12). It is likely that once the optimal drug dosage and combinations are developed, these agents may have even more substantial effect on survival in kidney cancer $(10,12)$. The most recent approval of the drug temsirolimus (CCI-779; Torisel, Wyeth), the first mammalian target of rapamycin inhibitor, offers an alternative for patients failing the kinase inhibitors, although the toxicity of this drug is greater (13-15). Torisel provides significantly higher median overall survival and progression-free survival compared with IFN- $\alpha$ (15-17). Although prolonged remissions are occasionally seen, the benefit offered by these agents is most often short lived, and there is a clear need for development of more effective therapies.

A potential approach for improving the therapeutic efficacy of targeted therapy for kidney cancer could be to target the underlying mechanisms responsible for drug resistance or radiation resistance. Kidney cancer cells express high levels of multiple membrane

Requests for reprints: Sharad S. Singhal, Department of Molecular Biology and Immunology, University of North Texas Health Science Center, 3500 Camp Bowie Boulevard, EAD Room 542, Fort Worth, TX 76107-2699. Phone: 817-735-0459; Fax: 817-735-2118; ssinghal@hsc.unt.edu.

Note: Supplementary data for this article are available at Cancer Research Online (http://cancerres.aacrjournals.org/).

Disclosure of Potential Conflicts of Interest

No potential conflicts of interest were disclosed. 
transporters that can participate in drug resistance and may also play some role in radiation resistance $(18,19)$. The majority of these belong to the ATP-binding cassette (ABC) family of proteins. Clinically, however, inhibitors of ABC transporters have not yet been successful in improving chemotherapeutic outcomes $(20,21)$, indicating that other resistance mechanisms are involved (22). Prominent among these other mechanisms are reduced glutathione (GSH), glutathione synthetase, glutathione reductase, glutathione $S$-transferases (GST), cytochrome P450s, $\gamma$-glutamyl transpeptidase, and the components of mercapturic acid pathway including the transporters for GSH conjugates (GS-E).

RLIP76 (RALBP1 gene product) is a stress-responsive, multi-functional transporter protein for GS-E as well as several toxic compounds, including chemotherapy drugs. It is frequently over-expressed in malignant cells and functions to oppose apoptosis by limiting the accumulation of endogenous or exogenous toxic electrophilic compounds in cells. RLIP76 was cloned originally as a Ral-binding GTPase-activating protein through a yeast twohybrid screen (23). It is a 76-kDa protein, but it appears as a 95-kDa band in SDS-PAGE (24). Tissue-purified as well as recombinant RLIP76 has been shown to function in isolated in vitro systems as well as in vivo studies to be an ATP-dependent transporter of GS-E as well as of the amphiphilic anticancer drugs such as doxorubicin (Adriamycin), vincristine, vinblastine, and vinorelbine (24-28). Studies showing the marked enhancement of vinorelbine efficacy in lung cancer and colon cancer xenografts by concomitant depletion or inhibition of RLIP76 have confirmed the in vivo relevance of these observations (29).

Recent studies have established that in human and rodent tissues and cells, RLIP76 is a major GS-E transporter (24-28,30-33). Whereas several ABC transporters such as multidrug resistance protein (MRP) 1, MRP3, MRP5, and BCRP do catalyze transport of GS-E, individually, each transporter represents a fraction of the total GS-E efflux capacity of cells $(34,35)$. In contrast, genetic deletion of the non-ABC transporter RLIP76 (76-kDa splice variant encoded by the human $R A L B P 1$ gene, functionally and structurally homologous to corresponding splice variant in mouse and rat, Ralbp1, which is encoded by the rodent Ralbpl gene) causes loss of about four fifths of total transport activity for GS-E. The loss transport of GS-E in RLIP76 knockout mice results in accumulation of GS-E and their electrophilic precursors (e.g., GS-HNE and 4HNE) in the tissues of these animals (36), and GST activity is reversibly inhibited due to accumulation of GS-E (37). These studies suggest that RLIP76 could be a very convenient single target that if depleted or inhibited could cause global inhibition of the mercapturic acid pathway.

Complete and sustained regressions of human non-small cell lung cancer (NSCLC) and colon cancer xenografts by systemic depletion or antibody-mediated inhibition clearly show the effectiveness of targeting the mercapturic acid pathway through RLIP76 (29). Syngeneic mouse B16 melanoma, a highly resistant malignancy, underwent a near complete regression (38); in addition, cell culture studies have shown that inhibiting or depleting RLIP76 causes apoptosis in several histologic types of malignancy, including leukemia, prostate cancer, and ovarian cancer. Significant expression of RLIP76 was previously shown in normal mouse kidney tissues (25) but not directly in kidney cancer cells. Because preliminary studies in cultured kidney cancer cells confirmed high expression of RLIP76, consistent with gene expression analyses, we carried out the present studies to determine whether RLIP76 depletion can be used to target kidney cancer.

\section{Materials and Methods}

\section{Reagents}

RPMI 1640 and DMEM, PBS, penicillin/streptomycin solution, fetal bovine serum (FBS), trypsin-EDTA, and trypan blue were purchased from Life Technologies, Inc. DMSO, G418 
(geneticin), and 3-(4,5-dimethylthiazol-2-yl)-2,5-diphenyltetrazolium bromide (MTT) were obtained from Sigma. Doxorubicin was obtained from Adria Laboratories. ${ }^{14} \mathrm{C}$-doxorubicin (specific activity, $44.8 \mathrm{Ci} / \mathrm{mmol}$ ) was purchased from NEN Life Sciences. Source of polyclonal rabbit anti-human rec-RLIP76 antibodies and protocol for purification of IgG were the same as previously described (24). Terminal deoxynucleotidyl transferasemediated dUTP nick end labeling (TUNEL) fluorescence detection kit was purchased from Promega. Dinitrophenyl $S$-glutathione (DNP-SG) was synthesized from 1-chloro-2,4dinitrobenzene and GSH according to the method described by us previously (24). The sources of other chemicals used in this study were the same as described previously $(24,39)$.

\section{Cell lines and cultures}

Human kidney normal (mesangial) and cancer (Caki-2) cell lines were purchased from the American Type Culture Collection. All cells were cultured at $37^{\circ} \mathrm{C}$ in a humidified atmosphere of 5\% $\mathrm{CO}_{2}$ in RPMI 1640 supplemented with $10 \%$ (v/v) heat-inactivated FBS, $1 \%$ (v/v) penicillin/streptomycin solution, $2 \mathrm{mmol} / \mathrm{L}$ L-glutamine, $10 \mathrm{mmol} / \mathrm{L}$ HEPES, 1 $\mathrm{mmol} / \mathrm{L}$ sodium pyruvate, $4.5 \mathrm{~g} / \mathrm{L}$ glucose, and $1.5 \mathrm{~g} / \mathrm{L}$ sodium bicarbonate.

\section{Anti-RLIP76 antibodies}

We have raised and purified polyclonal rabbit anti-human RLIP76 IgG using procedures described previously (24) and aliquots were stored at $-86^{\circ} \mathrm{C}$. All reagents for the preparation of antibodies and storage were filtered through $0.22-\mu \mathrm{m}$ filters and handled under laminar flow hoods in a sterile manner. Aerobic, anaerobic, and fungal cultures of random aliquots were performed at 2-mo intervals. The integrity and purity of the antibodies were consistently checked by SDS-PAGE and Western blot analysis against anti-IgG antibodies during these studies. Protein A affinity-purified immunoglobulin fraction obtained from the preimmune serum was used as control. Anti-RLIP76 IgG used in these experiments was previously shown by Ouchterlony double immunodiffusion assay to be non-cross-reactive with any other proteins, including P-glycoprotein or MRP1 $(30,40)$.

\section{RLIP76 small interfering RNA preparation}

RLIP76 small interfering RNA (siRNA) was purchased from Dharmacon Research, as described previously (41).

\section{RLIP76 phosphorothioate antisense DNA preparation}

RLIP76 antisense was purchased from Biosynthesis, Inc., as described previously (38).

\section{Drug sensitivity (MTT) assay}

Cell number $/ \mathrm{mL}$ in an aliquot of cells growing in log phase was determined by counting trypan blue-excluding cells in a hemocytometer, and 20,000 cells were plated into each well of 96-well flat-bottomed microtiter plates. After $12 \mathrm{~h}$ of incubation at $37^{\circ} \mathrm{C}$, medium containing either preimmune IgG or anti-RLIP76 IgG was added to cells. After 24 to $48 \mathrm{~h}$ of incubation, $20 \mu \mathrm{L}$ of $5 \mathrm{mg} / \mathrm{mL}$ MTT were introduced to each well and incubated for $2 \mathrm{~h}$ of exposure. The plates were centrifuged and medium was decanted. Cells were subsequently dissolved in $100 \mu \mathrm{L}$ DMSO with gentle shaking for $2 \mathrm{~h}$ at room temperature followed by measurement of absorbance at $570 \mathrm{~nm}$ (41). Eight replicate wells were used at each point in each of three separate measurements. Measured absorbance values were directly linked with a spreadsheet for calculation of $\mathrm{IC}_{50}$, defined as the drug concentration that reduced formazan formation by $50 \%$. Depletion of RLIP76 expression in cells by RLIP76 siRNA and RLIP76 antisense was measured as follows: cells were incubated for $3 \mathrm{~h}$ with 0 to $4 \mu \mathrm{g} /$ well of either RLIP76 siRNA or antisense in TransMessenger Transfection Reagent 
(Qiagen) and Maxfect Transfection Reagent (Molecula, Inc.), respectively, according to the manufacturer's provided protocol.

\section{Preparations of total crude membrane fractions for Western blot analyses}

Crude membrane fractions were prepared from the normal and cancer cell lines using established procedures as described previously (38). Levels of RLIP76 protein in normal and cancer cells were measured by ELISA assay using anti-RLIP76 IgG as previously described (41). Purified rec-RLIP76 with purity assessed by amino acid composition analysis was used to generate calibration curves.

\section{Purification of RLIP76}

DNP-SG affinity resin was prepared as described previously (24). All buffers used for purification were prepared fresh and filtered through sterilized $0.22-\mu \mathrm{m}$ membrane. Affinity purification of RLIP76 from human kidney cells was carried out in a manner identical to that described previously for human lung cancer cell lines (40). Because polidocanol interfered with Bradford reagent, protein was estimated by the method of Minamide and Bamburg (42). SDS-PAGE and Western blot analyses were performed by the method as described previously $(24,39)$.

\section{Preparation of RLIP76 liposomes}

rec-RLIP76 was purified by DNP-SG affinity chromatography as previously described from transformed Escherichia coli BL21 expressing the full-length (1,968 bp) RLIP76 cDNA in PET30a (+) prokaryotic expression plasmid and purity was confirmed by SDS-PAGE, Western blot, amino acid composition analyses, and matrix-assisted laser desorption/ ionization-mass spectrometry. To prepare proteoliposomes, purified RLIP76 was dialyzed against reconstitution buffer $\left[10 \mathrm{mmol} / \mathrm{L}\right.$ Tris- $\mathrm{HCl}(\mathrm{pH} \mathrm{7.4}), 4 \mathrm{mmol} / \mathrm{L} \mathrm{MgCl}_{2}, 1 \mathrm{mmol} / \mathrm{L}$ EGTA, $100 \mathrm{mmol} / \mathrm{L} \mathrm{KCl}, 40 \mathrm{mmol} / \mathrm{L}$ sucrose, $2.8 \mathrm{mmol} / \mathrm{L} \beta$-mercaptoethanol, $0.05 \mathrm{mmol} / \mathrm{L}$ butylated hydroxytoluene, $0.025 \%$ polidocanol]. An aqueous emulsion of soybean asolectin $(40 \mathrm{mg} / \mathrm{mL})$ and cholesterol $(10 \mathrm{mg} / \mathrm{mL})$ was prepared in the reconstitution buffer by sonication, from which a $100 \mu \mathrm{L}$ aliquot was added to $0.9 \mathrm{~mL}$ of dialyzed purified RLIP76 protein. After sonication of the resulting mixture for $30 \mathrm{~s}$ at $50 \mathrm{~W}, 200 \mathrm{mg}$ of SM-2 Biobeads preequilibrated with reconstitution buffer (without polidocanol) were added to initiate vesiculation, and after $4 \mathrm{~h}$ of incubation at $4{ }^{\circ} \mathrm{C}, \mathrm{SM}-2$ beads were removed by centrifugation at 3,620 $\times g$ and the vesicles (RLIP76 liposomes) were collected. Control liposomes were prepared using an equal amount of crude protein from E. coli not expressing RLIP76 (24).

\section{Transport studies in artificial liposomes}

Transport studies in proteoliposomes were done by the same method as described previously (24). No-protein proteoliposomes were used as negative controls.

\section{Transport studies in inside-out vesicles}

Inside-out vesicles (IOV) were prepared from the human kidney cell lines as described by us for the K562 cells (24). Transport studies of doxorubicin and DNP-SG in IOV were performed by the method as described previously (24). ATP-dependent uptake of ${ }^{14} \mathrm{C}$ doxorubicin was determined by subtracting the radioactivity $(\mathrm{cpm})$ of the control without ATP from that of the experimental containing ATP and the transport of doxorubicin was calculated in terms of $\mathrm{pmol} / \mathrm{min} / \mathrm{mg}$ IOV protein. The transport of ${ }^{3} \mathrm{H}-\mathrm{DNP}-\mathrm{SG}$ was measured in a similar manner. 


\section{Animal model}

Hsd: athymic nude $n u / n u$ mice ( $~ 11$ wk old) were obtained from Harlan. All animal experiments were carried out in accordance with a protocol approved by the Institutional Animal Care and Use Committee. Thirty mice were divided into six groups of 5 animals (treated with preimmune serum, scrambled siRNA, scrambled antisense DNA, RLIP76 antibodies, RLIP76 siRNA, and RLIP76 antisense). All 30 animals were injected with $2 \times$ $10^{6}$ human kidney cancer cell (Caki-2) suspensions in $100 \mu \mathrm{L}$ PBS s.c. Animals were examined daily for signs of tumor growth. Treatment was administered when the tumor surface area exceeded $42 \mathrm{~mm}^{2}$ ( day 22). Treatment consisted of $200 \mu \mathrm{g}$ of either RLIP76 antibodies, siRNA, or antisense in $100 \mu \mathrm{L}$ PBS. Control groups were treated with $200 \mu \mathrm{g} /$ $100 \mu \mathrm{L}$ of either preimmune serum, scrambled siRNA, or scrambled antisense DNA. These animal studies are necessary for development of kidney cancer xeno-grafts in nude mice. Tumors were measured in two dimensions by calipers using Study Director Software V1.6 from Studylog System. We have obtained the software that automates this analysis.

\section{Effect of RLIP76 antibody, siRNA, and antisense on apoptosis by TUNEL assay}

In these studies, we assessed whether cellular levels of RLIP76 could be depleted by RLIP76 antibody-mediated, RLIP76 siRNA-mediated, or RLIP76 antisense-mediated delivery to cultured kidney cancer cells and assessed whether uptake is correlated with apoptosis by the TUNEL assay. The Caki-2 kidney cancer cells $\left(1 \times 10^{6}\right)$ were grown on the coverslips. The cells were treated with RLIP76 antibody ( $40 \mu \mathrm{g} / \mathrm{mL}$ final concentration) or transfected with either RLIP76 siRNA ( $20 \mu \mathrm{g} / \mathrm{mL}$ final concentration) or antisense ( $10 \mu \mathrm{g} /$ $\mathrm{mL}$ final concentration). After $24 \mathrm{~h}$ of incubation, the medium was removed and cells were washed with PBS. TUNEL assay was performed using Promega fluorescence detection kit according to the protocol provided by the manufacturer and described by us previously (39).

\section{Annexin V apoptosis assays: effect of RLIP76 antibody, siRNA, and antisense on apoptosis by FITC-labeled Annexin V conjugate assay}

Early apoptosis was measured by studying the loss of membrane asymmetry using Annexin V staining analyzed by flow cytometry according to the method of Hammill and colleagues (43). Briefly, Caki-2 cells $\left(0.5 \times 10^{6} / \mathrm{mL}\right)$ were grown in six-well plate and treated with preimmune serum, anti-RLIP76 IgG, scrambled siRNA, RLIP76 siRNA, scrambled antisense, and RLIP76 antisense (final concentration: antibody, $40 \mu \mathrm{g} / \mathrm{mL}$; siRNA, $20 \mu \mathrm{g} /$ $\mathrm{mL}$; and antisense, $10 \mu \mathrm{g} / \mathrm{mL}$ ). After $24 \mathrm{~h}$ of incubation, the cells were harvested and centrifuged at 1,500 $\times g$ for $5 \mathrm{~min}$. Cells were washed once with PBS and resuspended in $400 \mu \mathrm{L}$ of cold Annexin binding buffer containing $5 \mu \mathrm{L}$ of Annexin V-FITC and $5 \mu \mathrm{L}$ of 0.1 $\mathrm{mg} / \mathrm{mL}$ propidium iodide. Cells were incubated at room temperature for $10 \mathrm{~min}$ in the dark and analyzed by flow cytometry using a Beckman Coulter Cytomics FC500 flow cytometer. Results were processed using CXP2.2 analysis software from Beckman Coulter (39).

\section{Results and Discussion}

\section{Expression and transport function of RLIP76 in kidney cells}

Western blot analyses of membrane protein extracts from human kidney normal (mesangial) and malignant (Caki-2) cells were performed against anti-RLIP76 IgG, indicating relatively larger amounts of RLIP76 in Caki-2 ( 3-fold) versus mesangial cells (Fig. 1A). The specificity of anti-RLIP76 IgG used for Western blot analyses was evident from comparison of peptide bands seen in Western blot analyses of crude protein fraction (Fig. 1) with those seen in SDS-PAGE or Western blot analyses of the purified protein (Fig. $1 B$ and $C$, respectively). RLIP76 from human kidney normal (mesangial) and cancer (Caki-2) cells was purified by an identical protocol of GS-E affinity chromatography used by us previously to 
purify rec-RLIP76 from transformed E. coli (24). In reduced denaturing gels, purified RLIP76 from both mesangial and Caki-2 cells showed two bands corresponding to the $M_{\mathrm{r}}$ values of 95 and $67 \mathrm{kDa}$ (Fig. $1 B$ ) and both bands were recognized by anti-RLIP76 IgG in Western blot analyses (Fig. 1C). Previous studies in our laboratory (24) and by other investigators (23) have shown that although the estimated molecular weights of RLIP76 and its rat and mouse orthologs (RalBP1 and RIP, respectively) are $\sim 76 \mathrm{kDa}$, these proteins show bands at higher $M_{\mathrm{r}}$ values $(95 \mathrm{kDa})$ in SDS gels. Lower molecular weight bands that arise from their proteolytic fragmentation are also observed $(23,24,40)$. Taken together, these results indicated that GS-E affinity chromatography purification yielded apparently homogenous RLIP76 from kidney cell lines.

The results of RLIP76 protein and transport activity are presented in Table 1 and show that the amounts of total crude membrane proteins obtained from $100 \times 10^{6}$ cells in log phase growth were comparable for mesangial $(7.73 \pm 0.52 \mathrm{mg})$ and Caki-2 $(7.42 \pm 0.38 \mathrm{mg})$ cells. Although a relatively greater amount of RLIP76 protein in Caki-2 (46 $\pm 3 \mu \mathrm{g})$ compared with mesangial $(17 \pm 2 \mu \mathrm{g})$ cells. RLIP76 protein represented a $0.22 \%$ and $0.62 \%$ of the total detergent-soluble protein from the membranes of mesangial and Caki-2 cells, respectively. These values of percentage of total membrane protein are in the range of those seen in both SCLC and NSCLC $(0.53 \pm 0.04 \%$ in SCLC, $n=6$, versus $0.57 \pm 0.07 \%$ in NSCLC, $n=6$; ref. 38). We have shown that proteoliposomes reconstituted with RLIP76 mediate ATPdependent transport of doxorubicin and other drugs $(24,44)$. To examine whether differential RLIP76 protein in mesangial and Caki-2 cells was reflected in their transport activity, we compared the ATP-dependent uptake of doxorubicin and DNP-SG in crude membrane IOVs prepared separately from the membranes of mesangial and Caki- 2 cells. The results presented in Table 1 clearly showed that the ATP-dependent transport of doxorubicin and DNP-SG was significantly higher in IOVs prepared from Caki-2 cells than from mesangial cells. Results of measurements of ATP-dependent transport of ${ }^{14} \mathrm{C}$-doxorubicin and ${ }^{3} \mathrm{H}-$ DNP-SG revealed greater transport of both substrates in Caki- 2 cells containing greater amounts of RLIP76 protein and a general correlation between RLIP76 protein level and transport activity (Table 1). Greater RLIP76 expression corresponded to greater transport activity.

\section{RLIP76 inhibition or depletion caused cytotoxicity in malignant cells}

The cytotoxic effects of RLIP76 inhibition by anti-human RLIP76 antibodies or the depletion of RLIP76 by using either siRNA or antisense phosphorothioate oligodeoxynucleotide (R508) was assessed by an established MTT cytotoxicity method (41). Cells were treated with preimmune IgG, scrambled siRNA, scrambled antisense, antiRLIP76 IgG, RLIP76 siRNA, or RLIP76 antisense for 24 hours. The toxicity of all three targeting agents was preferentially directed to the malignant cells compared with nonmalignant cells, an observation we have seen with other malignant (lung, ovary, prostate, and breast) compared with nonmalignant cell lines $(29,38)$. In contrast with the results seen with lung or colon cancer previously (in which all three modalities gave similar results), antisense was significantly more effective in killing kidney cancer cells than the antibody (Fig. 2A), and this difference could be related to factors in kidney cancers that reduce the effectiveness of the antibody or perhaps due to a relatively greater role of some intracellular function of RLIP76 in kidney cancers. Effect of RLIP76 antisense revealed almost complete depletion of RLIP76 protein in Caki-2 cells after 24 hours at a concentration of $10 \mu \mathrm{g} / \mathrm{mL}$ shown by Western blot analyses (Fig. 2B). RLIP76 depletion by antisense was also examined in Caki-2 cells by immunohistochemistry. As shown in Fig. 2C, RLIP76 is immunohistochemically detectable in Caki-2 cells treated with the scrambled antisense. This is in stark contrast with RLIP76 antisense, which nearly completely depleted RLIP76 (Fig. $2 C$ ) and caused extensive apoptosis (Fig. 3). 


\section{Apoptosis caused by inhibition or depletion of RLIP76}

The mechanism of cytotoxicity was assessed by determining apoptosis through an immunohistochemical TUNEL assay (Fig. $3 A$ ) as well as flow cytometry for Annexin V and propidium iodide (Fig. $3 B$ ). The results of the TUNEL assay showed no detectable apoptosis in the cells treated with preimmune $\mathrm{IgG}$, scrambled siRNA, or scrambled antisense. Apoptosis was, however, seen in Caki-2 cells treated with anti-RLIP76 IgG, RLIP76 siRNA, or RLIP76 antisense. The Caki-2 cells were significantly more susceptible than mesangial cells to the cytotoxicity of RLIP76 antibodies, siRNA, and antisense. We did not see any apoptosis in mesangial cells by TUNEL (Fig. 3A). Because TUNEL detects the last steps in apoptosis, we measured Annexin $\mathrm{V}$ in cells counterstained with propidium iodide to examine for the presence of cells at earlier stage of apoptosis; necrotic cells are stained by propidium iodide. The Annexin V-positive fraction of cells was unaffected either by preimmune serum or by scrambled siRNA and scrambled antisense. The antisense approach caused the most dramatic effect on apoptosis and necrosis at 24 hours after exposure (Fig. $3 B)$.

\section{RLIP76 depletion caused regression of kidney cancer xenografts in nude mice}

The above observations of the antineoplastic effects of RLIP76 depletion were examined in a xenograft model of kidney cancer. Tumor-bearing animals with established s.c. implanted tumors $\left(\sim 200 \mathrm{~mm}^{3} ; 40 \mathrm{~mm}^{2}\right)$ were treated with $200 \mu \mathrm{g}$ of either RLIP76 antibody, RLIP76 siRNA, or RLIP76 antisense therapy on day 1 by i.p. injection. Treated animals had rapid and dramatic reductions in tumors, whereas uncontrolled growth was observed in the control groups. The remarkable contrast in the outcome of tumors in animals treated with RLIP76 antibody, RLIP76 siRNA, or RLIP76 antisense versus preimmune serum, scrambled siRNA, or antisense was clearly evident for kidney cancer cell lines (Fig. 4A). The RLIP76 antibody-treated, RLIP76 siRNA-treated, or RLIP76 antisense-treated animals with kidney cancer were still alive at 177 days without evidence of recurrence. In comparison, all control animals were censored by day 42 (see Supplementary Figure). Weight gain was comparable with non-tumor-bearing controls, and no overt toxicity was evident. The effectiveness of the RLIP76 antisense to deplete RLIP76 in mouse tissues was shown in separate studies of nontumor-bearing C57B mice by sacrificing animals for analyses at 24 hours after a single i.p. dose of RLIP76 antisense (200 $\mu \mathrm{g} / 100 \mu \mathrm{L}$ PBS/mice). Western blot analyses of tissues confirmed detectable level of RLIP76 in tissues from scrambled antisense-treated animal and undetectable RLIP76 in RLIP76 antisense-treated animals (Fig. 4B).

Present studies show nearly complete and sustained regression of xenografts of Caki-2 kidney cancer by targeted inhibition or depletion of the mercapturic acid pathway transporter protein RLIP76. All three agents exhibited marked antineoplastic effects. These findings indicate that RLIP76 is a key survival protein for kidney cancer cell and that its depletion/inhibition results in regression of human kidney cancer xenografts without any apparent toxicity to animals. Whereas the in vitro effect of the antibody was relatively less than that of the antisense, the overall in vivo efficacy was quite similar. RLIP76 performs transport function when inserted in membrane (45), and other functions inside the cell, including regulation of the chaperone response to heat shock as a cytoplasmic binding protein for Hsf1 and cell cycle-specific termination of endocytosis in conjunction with cdc2 and GTPase activity toward cdc42 (46). Because the antibody functions to inhibit the transport activity of RLIP76 through binding to the cell surface epitope, which contains amino acids 171 to 185 (45), and does not deplete intracellular RLIP76 (or, presumably, interfere with its intracellular function), the somewhat greater efficacy of siRNA and antisense compared with the antibody suggests that in kidney cancer, intracellular functions of RLIP76 are significant contributors to the stress defense functions of RLIP76. The equal efficacy of the antibody and antisense in vivo could be due either to antibody-dependent 
cellular cytotoxicity or a greater role of the transport function of RLIP76 in vivo compared with cultured cells. Most importantly, equivalent outcomes achieved by depleting or inhibiting RLIP76 offer strong evidence for target specificity.

The marked effectiveness of this targeted therapy compares quite favorably with other promising targeted agents in kidney cancer. ZD1839 (gefitinib, Iressa), a tyrosine kinase inhibitor, caused reduction in the rate of growth of SKRC-49 renal cell xenografts in nude mice when administered by gavage daily for 15 days; the combination of paclitaxel and ZD1839 was more effective in slowing growth, but regression was not observed (47). Ly294002, a phosphatidylinositol 3-kinase (PI3K) inhibitor, did cause delayed and incomplete regression by 30 days in xenografts of 786-0 renal cell carcinoma (VHL deficient). When treatment was started before established visible tumor was present (48). Verotoxin, a Gb3 (globotriaosylceramide) targeting agent, did cause regression of very small tumors, but if treatment was started at the time of established ACHN renal cell tumors at least 6 to $7 \mathrm{~mm}$ in each dimension (as in our case), only relatively little growth inhibition was seen (49). An anti-CD26 monoclonal antibody was found effective in xenografts of Caki-2 (VHL expressing), but growth inhibition occurred rather than regression (50). The nuclear factor- $\kappa \mathrm{B}(\mathrm{NF}-\kappa \mathrm{B})$ targeted drug BAY-11-7085 has recently been shown to nearly completely inhibit the growth of established Caki-1 or 786-0 cell lines in xenografts but also did not cause regression (51). Incomplete regression was seen by day 30 in xenografts of SKRC-52 (VHL deficient) renal cell carcinoma treated with DAPT ( $\gamma$-secretase inhibitor) targeted at interrupting Notch signaling (52). Thus, targeted therapeutics for renal cell aimed at receptor tyrosine kinase, PI3K/Akt, NF-kB, or Notch do not seem as effective as RLIP76 inhibition or depletion in comparable animal xeno-graft models.

The greater effectiveness of RLIP76 targeted therapy can be understood in terms of a chemical as well as biochemical signaling model (Fig. 5). Acute depletion or inhibition of RLIP76 causes global changes in both chemical signaling as well as kinase-mediated signaling. Levels of proapoptotic alkenals and reactive oxygen species are increased several fold (36), and apoptosis has been shown to occur as a response to acute RLIP76 inhibition or depletion in NSCLC, SCLC, colon cancer, ovarian cancer, prostate cancer, and breast cancer previously $(29,38)$ and in kidney cancer in present studies. Alkenals, such as 4hydroxynonenal, are known to play a key concentration-dependent role in regulation of cell proliferation and apoptosis and are known to directly affect signaling in both intrinsic and extrinsic pathways of apoptosis. In homozygous RLIP76 knockout mouse and mouse embryonic fibroblast (MEF) studies, we have shown that levels of activated mitogenactivated protein kinase, Akt, and c-Jun $\mathrm{NH}_{2}$-terminal kinase are markedly increased; despite this increase, these knockout MEFs are an order of magnitude more sensitive to chemotherapy drugs or radiation $(31,36)$. RLIP76 knockout MEFs have near complete loss of clathrin-dependent endocytosis (31). Because clathrin-dependent endocytosis plays a key role as the first step in terminating ligand receptor signaling, an increase in these signaling pathways that are downstream of ligand receptor interactions is as expected; however, it is also apparent that these compensatory mechanisms are insufficient to defend cells from apoptosis caused by RLIP76 loss.

In conclusion, present studies show that inhibition or depletion of RLIP76 exerts antineoplastic effects in kidney cancer and indicate that this GS-E and xenobiotic transporters occupy a very important position in the hierarchy of stress defense mechanisms necessary for cancer cell survival.

\section{Supplementary Material}

Refer to Web version on PubMed Central for supplementary material. 


\section{Acknowledgments}

Grant support: NIH grants CA 77495 and CA 104661 (S. Awasthi), ES 012171 (Y.C. Awasthi), Cancer Research Foundation of North Texas (S.S. Singhal and S. Yadav), and Institute for Cancer Research and the Joe and Jessie Crump Fund for Medical Education (S.S. Singhal).

\section{References}

1. Eto M, Naito S. Molecular targeting therapy for renal cell carcinoma. Int J Clin Oncol 2006;11:20913. [PubMed: 16850127]

2. Costa LJ, Drabkin HA. Renal cell carcinoma: new developments in molecular biology and potential for targeted therapies. Oncologist 2007;12:1404-15. [PubMed: 18165617]

3. Stillebroer AB, Oosterwijk E, Oyen WJ, Mulders PF, Boerman OC. Radio-labeled antibodies in renal cell carcinoma. Cancer Imaging 2007;7:179-88. [PubMed: 18055291]

4. Mellado B, Gascón P. Molecular biology of renal cell carcinoma. Clin Transl Oncol 2006;8:706-10. [PubMed: 17074668]

5. Rutherford EE, Cast JE, Breen DJ. Immediate and long-term CT appearances following radiofrequency ablation of renal tumors. Clin Radiol 2008;63:220-30. [PubMed: 18194700]

6. Bankhead C. Three new drugs available to fight kidney cancer. J Natl Cancer Inst 2006;98:1181-2. [PubMed: 16954469]

7. Patel PH, Chadalavada RSV, Chaganti RSK, Motzer RJ. Targeting von Hippel-Lindau pathway in renal cell carcinoma. Clin Cancer Res 2006;12:7215-20. [PubMed: 17189392]

8. Adnane L, Trail PA, Taylor I, Wilhelm SM. Sorafenib (BAY 43-9006, Nexavar), a dual-action inhibitor that targets RAF/MEK/ERK pathway in tumor cells and tyrosine kinases VEGFR/PDGFR in tumor vasculature. Methods Enzymol 2006;407:597-612. [PubMed: 16757355]

9. Bhojani N, Jeldres C, Patard JJ, et al. Toxicities associated with the administration of sorafenib, sunitinib, and temsirolimus and their management in patients with metastatic renal cell carcinoma. Eur Urol 2008;53:917-30. [PubMed: 18054825]

10. Linehan WM, Vasselli J, Srinivasan R, et al. Genetic basis of cancer of the kidney: disease-specific approaches to therapy. Clin Cancer Res 2004;10:6282-9S.

11. Larkin JM, Eisen T. Kinase inhibitors in the treatment of renal cell carcinoma. Crit Rev Oncol Hematol 2006;60:216-26. [PubMed: 16860997]

12. Robb VA, Karbowniczek M, Klein-Szanto AJ, Henske EP. Activation of the mTOR signaling pathway in renal clear cell carcinoma. J Urol 2007;177:346-52. [PubMed: 17162089]

13. Thomas GV. mTOR and cancer: reason for dancing at the crossroads? Curr Opin Genet Dev 2006;16:78-84. [PubMed: 16359855]

14. Panner A, Nakamura JL, Parsa AT, et al. mTOR-independent translational control of the extrinsic cell death pathway by RalA. Mol Cell Biol 2006;26:7345-57. [PubMed: 16894031]

15. Gore ME. Temsirolimus in the treatment of advanced renal cell carcinoma. Ann Oncol 2007;18:87-8.

16. Hudes G, Carducci M, Tomczak P, et al. Temsirolimus, interferon alfa, or both for advanced renalcell carcinoma. N Engl J Med 2007;356:2271-81. [PubMed: 17538086]

17. Huang WC. Is advanced renal cell carcinoma best treated with temsirolimus, interferon $\alpha$, or both? Nat Clin Pract Oncol 2008;5:16-7. [PubMed: 17984986]

18. Longo R, D'Andrea MR, Sarmiento R, Salerno F, Gasparini G. Integrated therapy of kidney cancer. Ann Oncol 2007;18:141-8.

19. Langbein S, Frederiks WM, zur Hausen A, et al. Metastasis is promoted by a bioenergetic switch: new targets for progressive renal cell cancer. Int J Cancer 2008;122:2422-8. [PubMed: 18302154]

20. Pusztai L, Wagner P, Ibrahim N, et al. Phase II study of tariquidar, a selective P-glycoprotein inhibitor, in patients with chemotherapy-resistant, advanced breast carcinoma. Cancer 2005;104:682-91. [PubMed: 15986399]

21. Modok S, Mellor HR, Callaghan R. Modulation of multidrug resistance efflux pump activity to overcome chemoresistance in cancer. Curr Opin Pharmacol 2006;6:350-4. [PubMed: 16690355] 
22. Shukla S, Wu CP, Ambudkar SV. Development of inhibitors of ATP-binding cassette drug transporters: present status and challenges. Expert Opin Drug Metab Toxicol 2008;4:205-23. [PubMed: 18248313]

23. Jullien-Flores V, Dorseuil O, Romero F, et al. Bridging Ral GTPase to Rho pathways. RLIP76, a Ral effector with CDC42/Rac GTPase-activating protein activity. J Biol Chem 1995;270:22473-7. [PubMed: 7673236]

24. Awasthi S, Cheng J, Singhal SS, et al. Novel function of human RLIP76: ATP-dependent transport of glutathione conjugates and doxorubicin. Biochemistry 2000;39:9327-34. [PubMed: 10924126]

25. Awasthi S, Singhal SS, Yadav S, et al. RLIP76 is a major determinant of radiation sensitivity. Cancer Res 2005;65:6022-8. [PubMed: 16024601]

26. Awasthi S, Singhal SS, Srivastava SK, et al. Adenosine triphosphate-dependent transport of doxorubicin, daunomycin, and vinblastine in human tissues by a mechanism distinct from the Pglycoprotein. J Clin Invest 1994;93:958-65. [PubMed: 7907606]

27. Awasthi S, Singhal SS, Srivastava SK, et al. ATP-dependent human erythrocyte glutathioneconjugate transporter. I. Purification, photoaffinity labeling, and kinetic characteristics of ATPase activity. Biochemistry 1998;37:5231-8. [PubMed: 9548754]

28. Awasthi S, Singhal SS, Pikula S, et al. ATP-dependent human erythrocyte glutathione-conjugate transporter. II. Functional reconstitution of transport activity. Biochemistry 1998;37:5239-48. [PubMed: 9548755]

29. Singhal SS, Singhal J, Yadav S, et al. Regression of lung and colon cancer xenografts by depleting or inhibiting RLIP76 (RALBP1). Cancer Res 2007;67:4382-9. [PubMed: 17483352]

30. Awasthi S, Singhal SS, Sharma R, Zimniak P, Awasthi YC. Transport of glutathione-conjugates and chemo-therapeutic drugs by RLIP76: a novel link between G-protein and tyrosine kinase signaling and drug resistance. Int J Cancer 2003;106:635-46. [PubMed: 12866021]

31. Singhal SS, Yadav S, Singhal J, Sahu M, Sehrawat A, Awasthi S. Diminished drug transport and augmented radiation sensitivity caused by loss of RLIP76. FEBS Lett 2008;582:3408-14. [PubMed: 18789326]

32. Sharma R, Singhal SS, Cheng J, et al. RLIP76 is the major ATP-dependent transporter of glutathione-conjugates and doxorubicin in human erythrocytes. Arch Biochem Biophys 2001;391:171-9. [PubMed: 11437348]

33. Singhal SS, Yadav S, Roth C, Singhal J. RLIP76: a novel glutathione-conjugate and multi-drug transporter. Biochem Pharmacol 2009;77:761-9. [PubMed: 18983828]

34. Sarkadi B, Homolya L, Szakács G, Váradi A. Human multidrug resistance ABCB and ABCG transporters: participation in a chemo-immunity defense system. Physiol Rev 2006;86:1179-236. [PubMed: 17015488]

35. Borst P, Evers R, Kool M, Wijnholds J. The multidrug resistance protein family. Biochim Biophys Acta 1999;1461:347-57. [PubMed: 10581366]

36. Singhal J, Singhal SS, Yadav S, et al. RLIP76 in defense of radiation poisoning. Int J Radiat Oncol Biol Phys 2008;72:553-61. [PubMed: 18793957]

37. Awasthi S, Srivastava SK, Ahmad F, Ahmad H, Ansari GA. Interactions of glutathione $S$ transferase- $\pi$ with ethacrynic acid and its glutathione conjugate. Biochim Biophys Acta 1993;1164:173-8. [PubMed: 8329448]

38. Singhal SS, Awasthi YC, Awasthi S. Regression of melanoma in a murine model by RLIP76 depletion. Cancer Res 2006;66:2354-60. [PubMed: 16489041]

39. Singhal SS, Yadav S, Drake K, Singhal J, Awasthi S. Hsf-1 and POB1 induce drug-sensitivity and apoptosis by inhibiting Ralbp1. J Biol Chem 2008;283:19714-29. [PubMed: 18474607]

40. Singhal SS, Singhal J, Sharma R, et al. Role of RLIP76 in lung cancer doxorubicin resistance. I. The ATPase activity of RLIP76 correlates with doxorubicin and 4HNE resistance in lung cancer cells. Int J Oncol 2003;22:365-75. [PubMed: 12527936]

41. Singhal SS, Yadav S, Singhal J, et al. Depletion of RLIP76 sensitizes lung cancer cells to doxorubicin. Biochem Pharmacol 2005;70:481-8. [PubMed: 15950949]

42. Minamide LS, Bamburg JR. A filter paper dye-binding assay for quantitative determination of protein without interference from reducing agents or detergents. Anal Biochem 1990;190:66-70. [PubMed: 2285147] 
43. Hammill AK, Uhr JW, Scheuermann RH. Annexin V staining due to loss of membrane asymmetry can be reversible and precede commitment to apoptotic death. Expt Cell Res 1999;251:16-21.

44. Stuckler D, Singhal J, Singhal SS, Yadav S, Awasthi YC, Awasthi S. RLIP76 transports vinorelbine and mediates drug resistance in non-small cell lung cancer. Cancer Res 2005;65:9918. [PubMed: 15705900]

45. Yadav S, Singhal SS, Singhal J, et al. Identification of membrane anchoring domains of RLIP76 using deletion mutant analyses. Biochemistry 2004;43:16243-53. [PubMed: 15610018]

46. Hu Y, Mivechi NF. HSF1 interacts with Ral-binding protein 1 in a stress-responsive, multiprotein complex with HSP90 in vivo. J Biol Chem 2003;278:17299-306. [PubMed: 12621024]

47. Sumitomo M, Asano T, Asakuma J, Asano T, Horiguchi A, Hayakawa M. ZD1839 modulates paclitaxel response in renal cancer by blocking paclitaxel-induced activation of the epidermal growth factor receptor-extracellular signal-regulated kinase pathway. Clin Cancer Res 2004;10:794-801. [PubMed: 14760103]

48. Sourbier C, Lindner V, Lang H, et al. The phosphoinositide 3-kinase/Akt pathway: a new target in human renal cell carcinoma therapy. Cancer Res 2006;66:5130-42. [PubMed: 16707436]

49. Ishitoya S, Kurazono H, Nishiyama $H$, et al. Verotoxin induces rapid elimination of human renal tumor xenografts in SCID mice. J Urol 2004;171:1309-13. [PubMed: 14767339]

50. Inamoto $\mathrm{T}$, Yamochi $\mathrm{T}$, Ohnuma $\mathrm{K}$, et al. Anti-CD26 monoclonal antibody-mediated $\mathrm{G}_{1}-\mathrm{S}$ arrest of human renal clear cell carcinoma Caki-2 is associated with retinoblastoma substrate dephosphorylation, cyclin-dependent kinase 2 reduction, p27(kip1) enhancement, and disruption of binding to the extracellular matrix. Clin Cancer Res 2006;12:3470-7. [PubMed: 16740772]

51. Sourbier C, Danilin S, Lindner V, et al. Targeting the nuclear factor- $\kappa \mathrm{B}$ rescue pathway has promising future in human renal cell carcinoma therapy. Cancer Res 2007;67:11668-76. [PubMed: 18089796]

52. Sjölund J, Johansson M, Manna S, et al. Suppression of renal cell carcinoma growth by inhibition of Notch signaling in vitro and in vivo. J Clin Invest 2008;118:217-28. [PubMed: 18079963] 


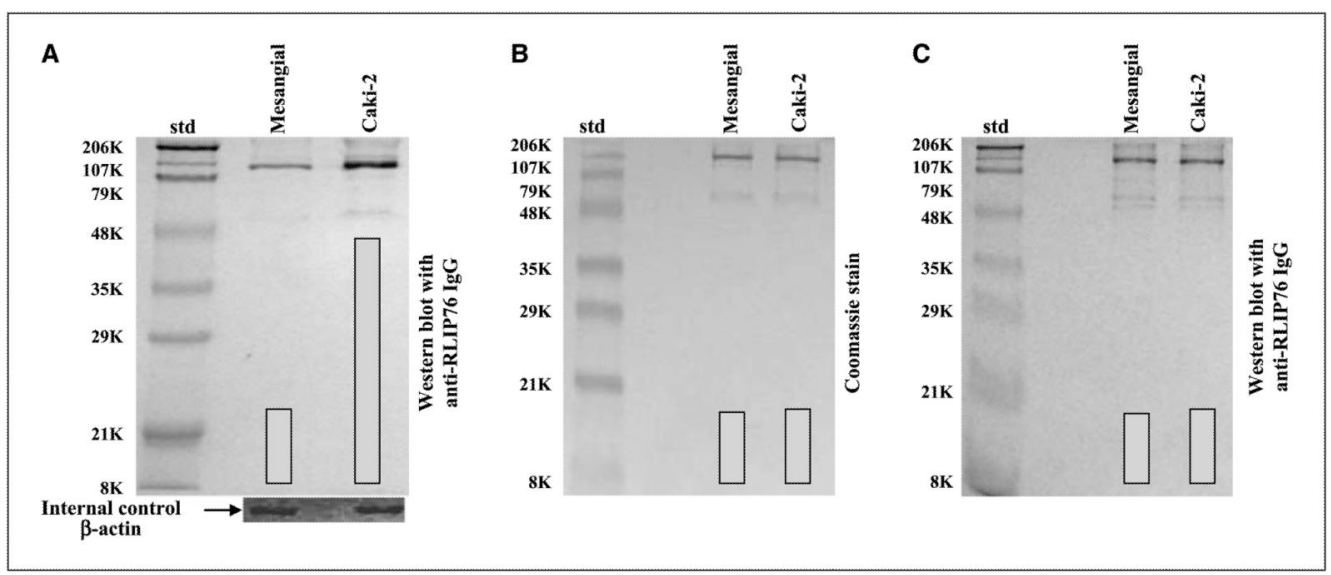

Figure 1.

RLIP76 levels in mesangial versus Caki-2 kidney carcinoma. $A$, aliquots of crude membrane fractions of cells, containing $200 \mu \mathrm{g}$ protein, were used for SDS-PAGE and Western blotting against anti-RLIP76 IgG as primary antibody and horseradish peroxidase-conjugated goat anti-rabbit IgG as secondary antibody and developed with 4-chloro-1-naphthol as chromogenic substrate. $\beta$-Actin was used as an internal control. DNP-SG-Sepharose affinity-purified RLIP76 from mesangial (control) and Caki-2 (malignant) human kidney cells ( $5 \mu \mathrm{g}$ protein) was applied to SDS-PAGE $(B)$ and subjected to Western blot analyses $(C)$. Results were quantified by scanning densitometry. 

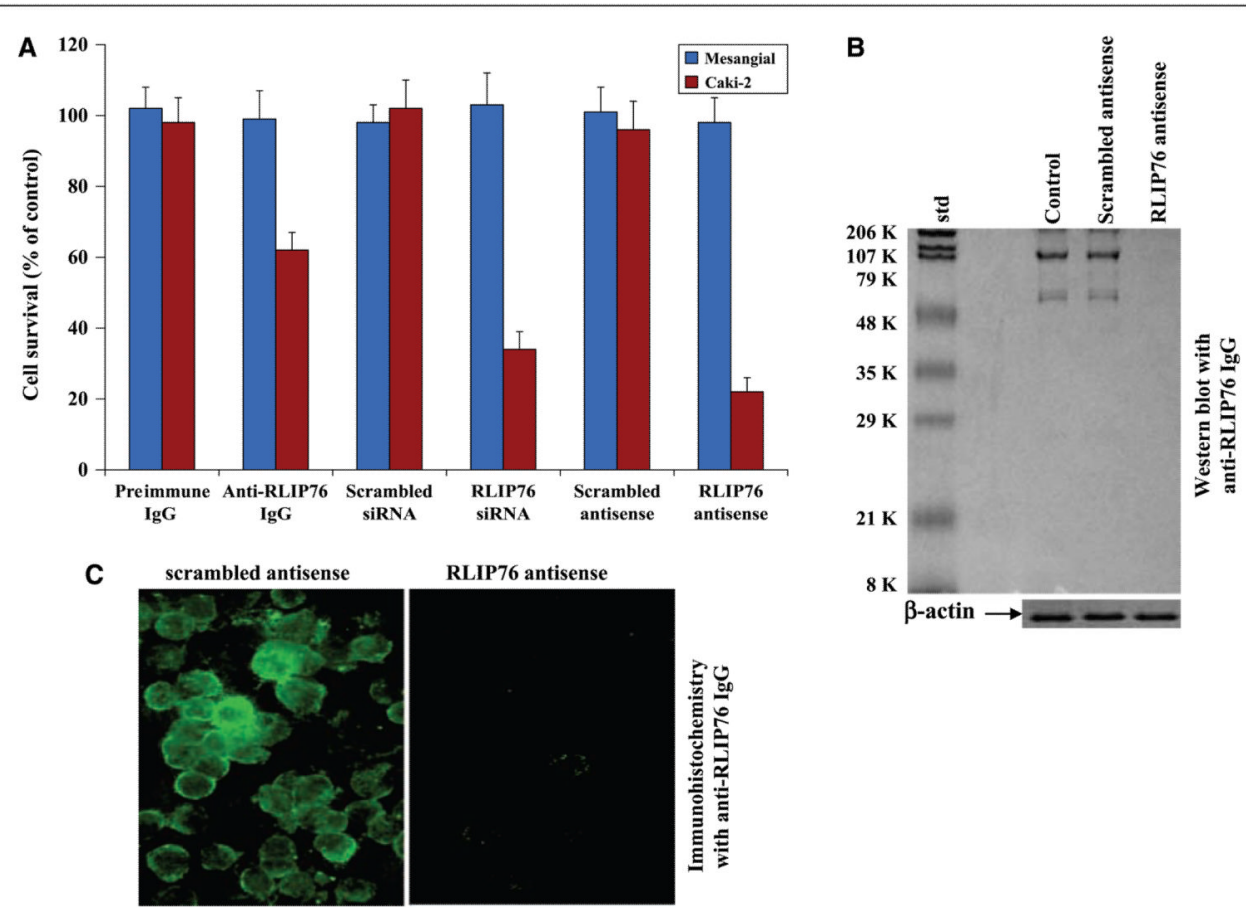

Figure 2.

Inhibition or depletion of RLIP76 selectively decreases survival of malignant Caki-2 kidney cancer cell compared with normal mesangial cells. A, effect of anti-RLIP76 IgG $(40 \mu \mathrm{g} / \mathrm{mL}$ final concentration) on cell survival was determined by MTT assay. Depletion of RLIP76 expression by RLIP76 siRNA (20 $\mu \mathrm{g} / \mathrm{mL}$ final concentration) and RLIP76 antisense (10 $\mu \mathrm{g} /$ $\mathrm{mL}$ final concentration) was done using TransMessenger Transfection Reagent kit and Maxfect Transfection Reagent according to the manufacturer's instructions, respectively. Cell survival was measured by MTT cytotoxicity assay $24 \mathrm{~h}$ after treatment. Columns, mean of two separate determinations with eight replicates each $(n=16)$; bars, SD. Blue columns, mesangial (normal) cells; red columns, Caki-2 kidney cancer cells. B, effect of RLIP76 antisense on the depletion of RLIP76 in Caki-2 cells (used $200 \mu \mathrm{g}$ crude protein in each case) by Western blotting with anti-RLIP76 IgG. $\beta$-Actin was used as an internal control. C, for immunohistochemical localization studies, anti-RLIP76 IgG was used as primary antibody and FITC-conjugated goat anti-rabbit IgG was used as secondary antibody. 

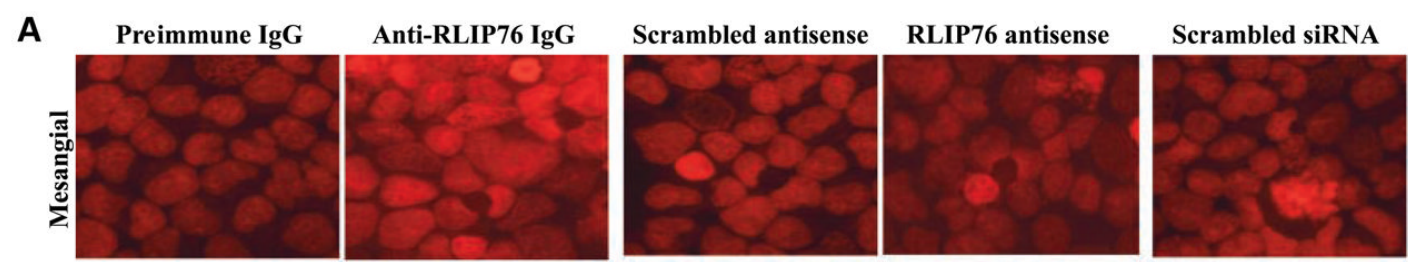

RLIP76 siRNA
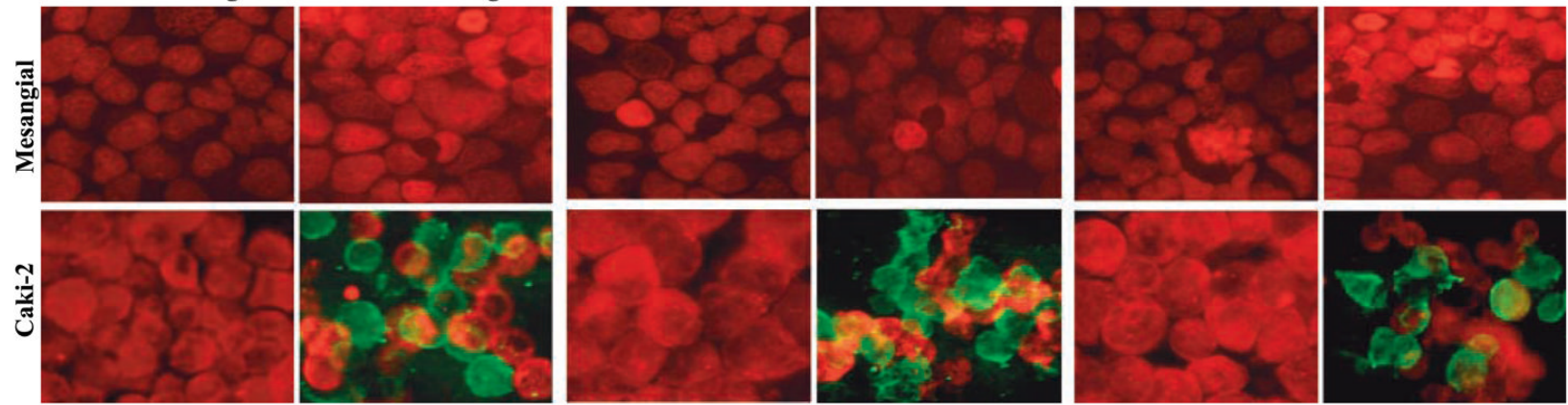

B
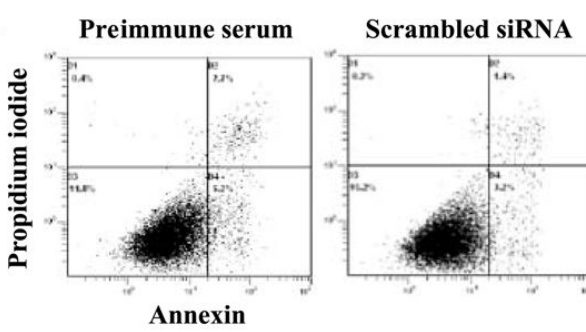

Scrambled antisense
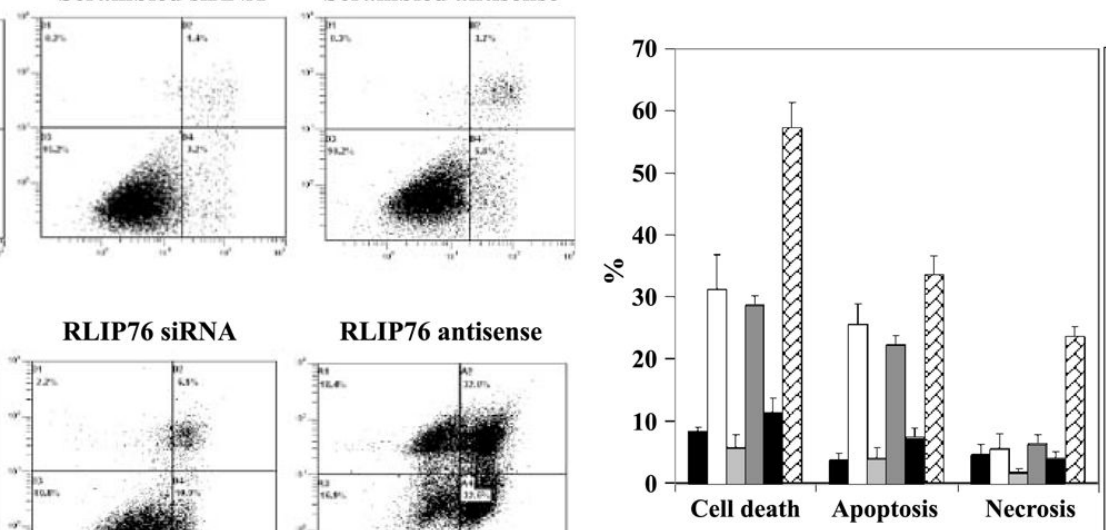

Preimmune serum Anti-RLIP76 IgG
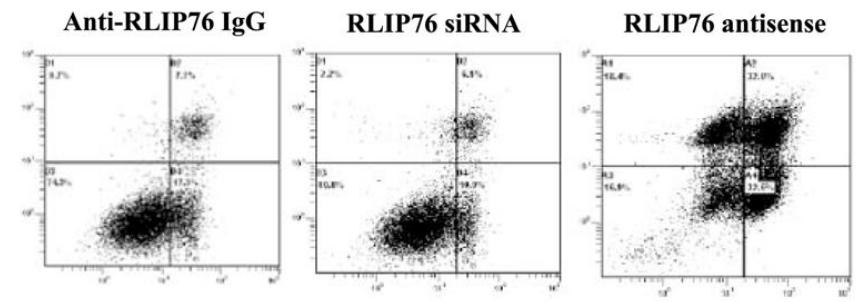

$\square$ Anti-RLIP76 IgG

Scrambled SiRNA

$\square$ RLIP76 SiRNA

Scrambled antisense

RLIP76 antisense

Figure 3.

$A$, effect of RLIP76 antibody, siRNA, and antisense on apoptosis by TUNEL assay. Cells were grown on coverslips. For anti-RLIP76 IgG treatment, cells were incubated with RLIP76 antibody ( $40 \mu \mathrm{g} / \mathrm{mL}$ concentration) for $24 \mathrm{~h}$; for siRNA treatment $(20 \mu \mathrm{g} / \mathrm{mL}$ final concentration), cells were transfected with TransMessenger Transfection Reagent; and for antisense treatment $(10 \mu \mathrm{g} / \mathrm{mL}$ final concentration), cells were transfected with Maxfect Transfection Reagent before TUNEL assay using Promega fluorescence detection kit and examined using Zeiss LSM 510 META laser scanning fluorescence microscope with filters $520 \mathrm{~nm}$ and $>620 \mathrm{~nm}$. Photographs taken at identical exposure at $\times 400$ magnification are presented. Apoptotic cells showed green fluorescence. B, effect of RLIP76 antibody, siRNA, and antisense on apoptosis and necrosis by flow cytometry. Caki-2 cells $\left(0.5 \times 10^{6} \%\right.$ $\mathrm{mL}$ ) were grown in six-well plate and treated with preimmune serum, anti-RLIP76 IgG, scrambled siRNA, RLIP76 siRNA, scrambled antisense, and RLIP76 antisense (final concentration: antibody, $40 \mu \mathrm{g} / \mathrm{mL}$; siRNA, $20 \mu \mathrm{g} / \mathrm{mL}$; antisense, $10 \mu \mathrm{g} / \mathrm{mL}$ ). After $24 \mathrm{~h}$ of incubation, the cells were harvested and centrifuged at $1,500 \times g$ for $5 \mathrm{~min}$. Cells were washed once with PBS and resuspended in $400 \mu \mathrm{L}$ cold Annexin binding buffer containing 5 $\mu \mathrm{L}$ of Annexin V-FITC and $5 \mu \mathrm{L}$ of $0.1 \mathrm{mg} / \mathrm{mL}$ propidium iodide. Cells were incubated at room temperature for $10 \mathrm{~min}$ in the dark and analyzed by flow cytometry using a Beckman Coulter Cytomics FC500 flow cytometer. Results were processed using CXP2.2 analysis software. 


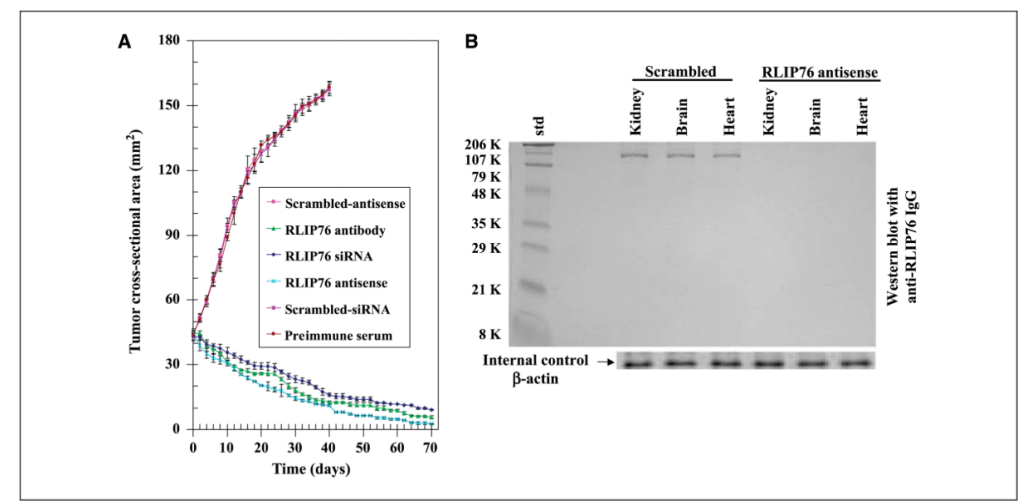

Figure 4.

Treatment with RLIP76 antibody, siRNA, or antisense causes regression of established Caki-2 kidney cancer xenografts. A, for xenograft studies, we used thirty 11-wk-old Hsd:athymic nude $n u / n u$ mice (Harlan) and randomized five animals each into six groups as follows: (a) preimmune serum, $(b)$ scrambled siRNA, $(c)$ scrambled antisense DNA, $(d)$ RLIP76 antibodies, $(e)$ RLIP76 siRNA, and (f) RLIP76 antisense. All 30 animals were injected with $2 \times 10^{6}$ human kidney cancer cell (Caki-2) suspensions in $100 \mu \mathrm{L}$ PBS s.c. into one flank of each $n u / n u$ nude mouse. Animals were examined daily for signs of tumor growth. When tumors reached a cross-sectional area of $\sim 42 \mathrm{~mm}^{2}$ ( $22 \mathrm{~d}$ later), animals were randomized to treatment groups as indicated in the figure. Treatment consisted of $200 \mu \mathrm{g}$ of either RLIP76 antibodies, siRNA, or antisense in $100 \mu \mathrm{L}$ PBS. Control groups were treated with $200 \mu \mathrm{g} / 100 \mu \mathrm{L}$ of either preimmune serum, scrambled siRNA, or scrambled antisense DNA. Tumors were measured in two dimensions using calipers. Tumor measurements are presented with all control groups (preimmune IgG, scrambled siRNA, or antisense) versus all treated groups (anti-RLIP76 IgG, RLIP76 siRNA, or antisense). $B$, the ability of the RLIP76 antisense (R508) to completely deplete RLIP76 protein in RLIP76 ${ }^{+/+}$animals was tested in C57B mice sacrificed at $24 \mathrm{~h}$ after one dose of scrambled (control group) or R508 $(0.2 \mathrm{mg}$ in $0.1 \mathrm{~mL}$ PBS) i.p. Kidney, brain, and heart tissues were removed from animals and membrane fraction was prepared for Western blot analysis, with application of $200 \mu \mathrm{g}$ crude protein to SDS-PAGE and using anti-RLIP76 IgG as primary antibody, and $\beta$-actin was used as an internal control. 


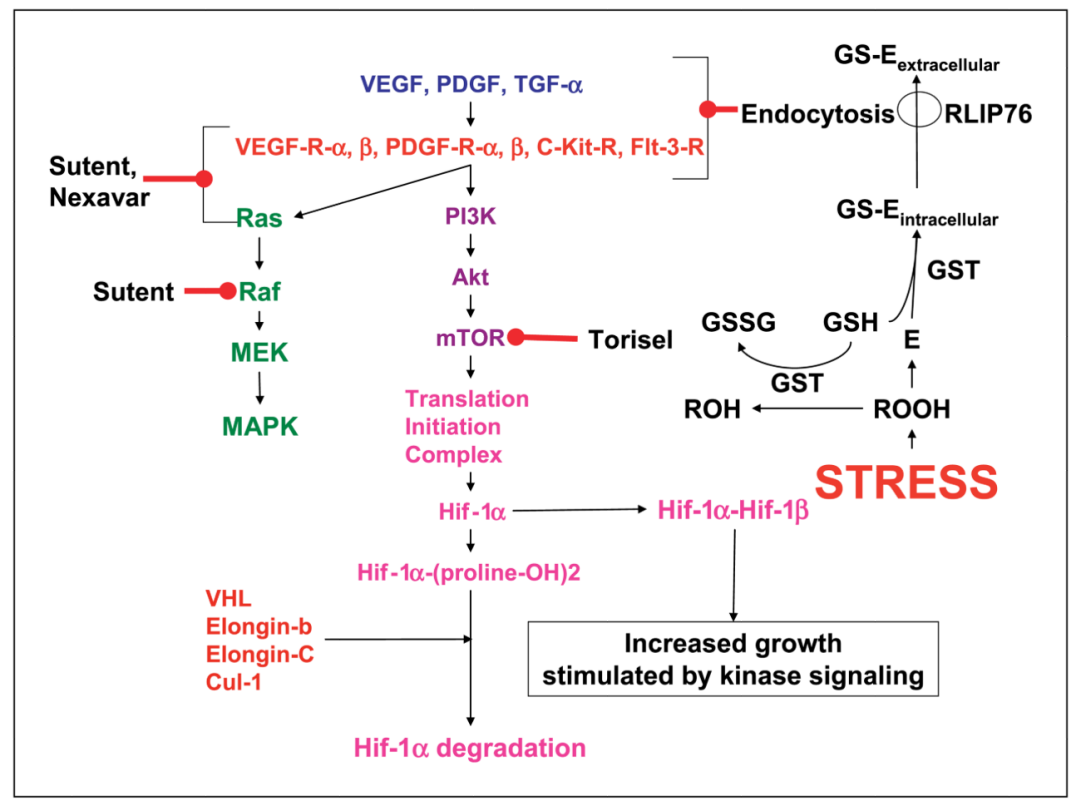

Figure 5.

A model for regulation of signaling by RLIP76. Stress (oxidant, radiant, signaling) causes production of lipid and other hydroperoxides $(\mathrm{ROOH})$, which are extremely reactive and capable of propagating the chain reaction of lipid peroxidation. The reduction of $\mathrm{ROOH}$ to $\mathrm{ROH}$ through peroxidases (prominently GSTs for lipid hydroperoxides) is linked to the oxidation of GSH to glutathionyl disulfide $(G S S G)$. E, electrophilic species including epoxides and alkenals that are generated as downstream (lower energy) by-products of $\mathrm{ROOH}$ (such as 4-hydroxynonenal). These are conjugated with GSH through GST-catalyzed reactions to form GS-E, which are subsequently transported out of the cell by RLIP76. RLIP76 thus represents a mechanism for coupling ATP hydrolysis-driven transmembrane efflux of dianionic GS-E with endocytosis of various receptor ligand complexes. RLIP76 is bound to the endocytosis complex through the clathrin adaptor AP2 as well as a complex of POB1/Epsin/Grb/Nck $(23,30)$. 


\section{Table 1}

RLIP76 protein and transport activity in human kidney normal (mesangial) and cancer (Caki-2) cells

\begin{tabular}{|lccccc|}
\hline & \multicolumn{2}{c}{ RLIP76 protein } & & \multicolumn{2}{c|}{ Transport activity (pmol/min/mg) } \\
\cline { 2 - 3 } \cline { 5 - 6 } & $\mathbf{\mu g} / \mathbf{1 0}^{\mathbf{8}}$ & Total crude protein (\%) & & ${ }^{\mathbf{1 4}} \mathbf{C}$-doxorubicin & ${ }^{\mathbf{3}} \mathbf{H}-\mathbf{D N P}-\mathbf{S G}$ \\
\hline Mesangial (normal) & $17 \pm 2$ & 0.22 & & $43 \pm 6$ & $138 \pm 14$ \\
Caki-2 (malignant) & $46 \pm 3$ & 0.62 & & $135 \pm 19$ & $716 \pm 64$ \\
\hline
\end{tabular}

NOTE: Cell lines were cultured in respective medium and homogenate was prepared from $100 \times 10^{6}$ cells. RLIP76 was purified from total crude membrane fraction using DNP-SG affinity column chromatography and quantified by ELISA. SDS-PAGE and Western blot of purified RLIP76 are presented in Fig. $1 B$ and $C$, respectively. For transport studies, IOVs prepared from $20 \times 10^{6}$ cells were enriched for IOVs by wheat germ agglutinin affinity chromatography (24). Transport activity was calculated from measurements of uptake of ${ }^{14} \mathrm{C}$-doxorubicin (specific activity, 8.5 $\times 10^{4} \mathrm{cpm} / \mathrm{nmol}$ ) and ${ }^{3} \mathrm{H}-\mathrm{DNP}-\mathrm{SG}$ (specific activity, $\left.3.6 \times 10^{3} \mathrm{cpm} / \mathrm{nmol}\right)$ into the IOVs $(20 \mu \mathrm{g} / 30 \mu \mathrm{L}$ reaction mixture) in the presence or absence of $4 \mathrm{mmol} / \mathrm{L}$ ATP as described (24). Each transport experiment was done in triplicates in three separate experiments $(n=9)$. 